\title{
Wenn Palmen im Palmenhaus zu groß werden
}

An der Spitze der Palmen befindet sich ein Vegetationskegel, an dem die Palme wächst und die neuen Blätter entstehen. Wird dieser (das Palmenherz) zerstört, stirbt die Palme. Deshalb können Palmen, die in Kultur und auch bei uns im Palmenhaus zu groß geworden sind, nicht einfach gekürzt werden, sie würden dadurch absterben. Wenn Palmen im Gewächshaus an das Glasdach stoßen und dabei ihre maximale Höhe noch nicht erreicht haben, würden sie weiter wachsen und dabei die Glasscheiben zerstören.

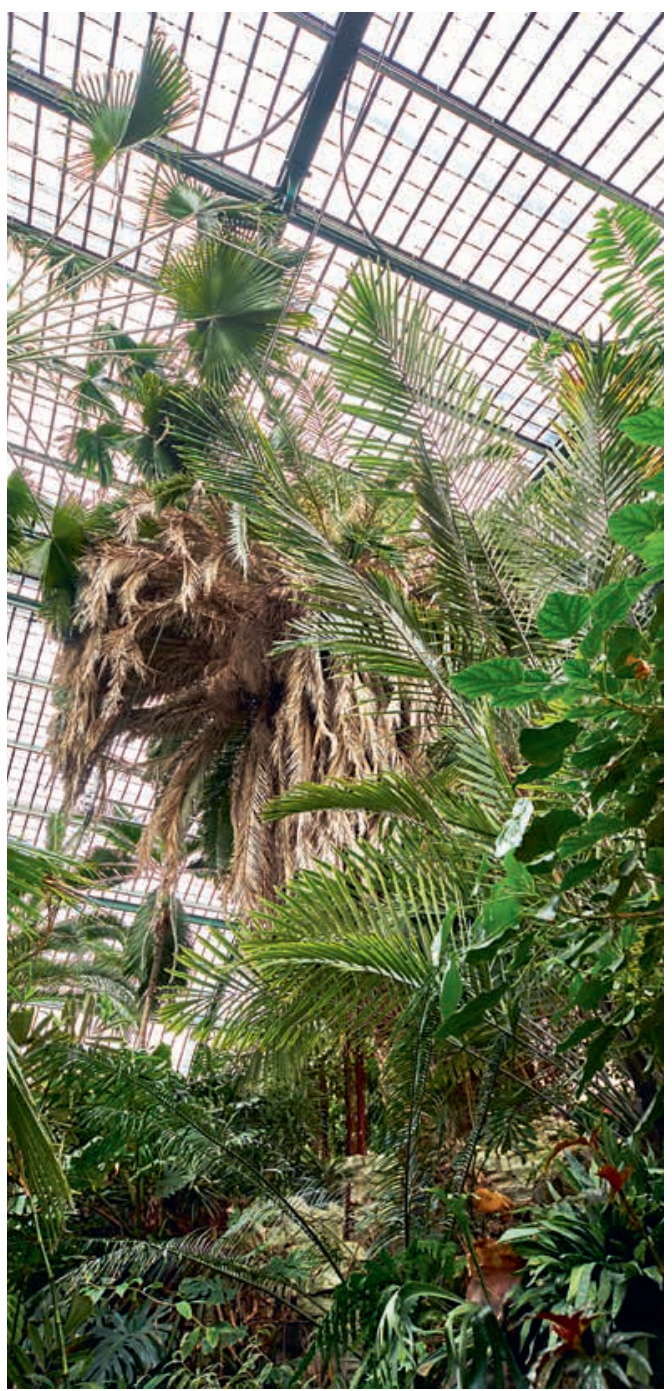

Im März 2019 musste deshalb in einer dreitägigen Aktion eine rund 70 Jahre alte und etwa 15 Meter hohe Kanarische Dattelpalme (Phoenix canariensis) gefällt werden, weil sie das Glasdach zu sprengen drohte. Die Fällaktion wurde von Toм Wolf fotografisch dokumentiert.

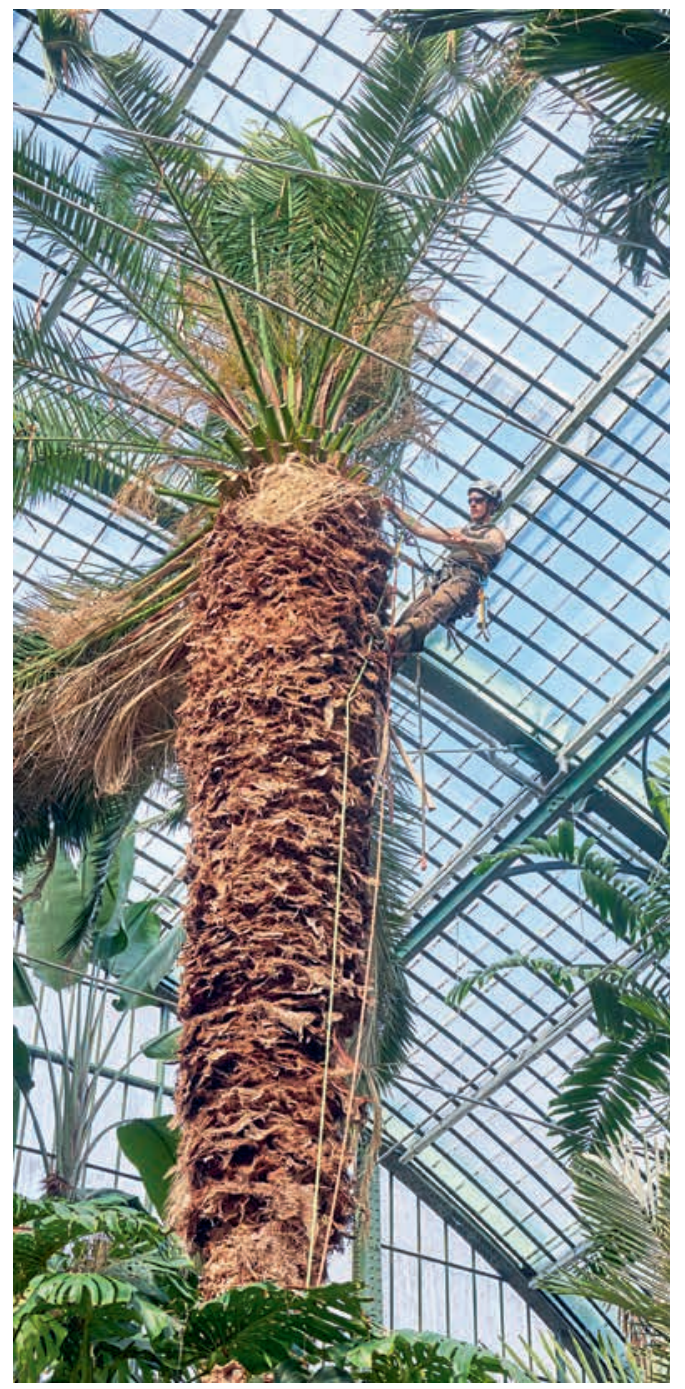



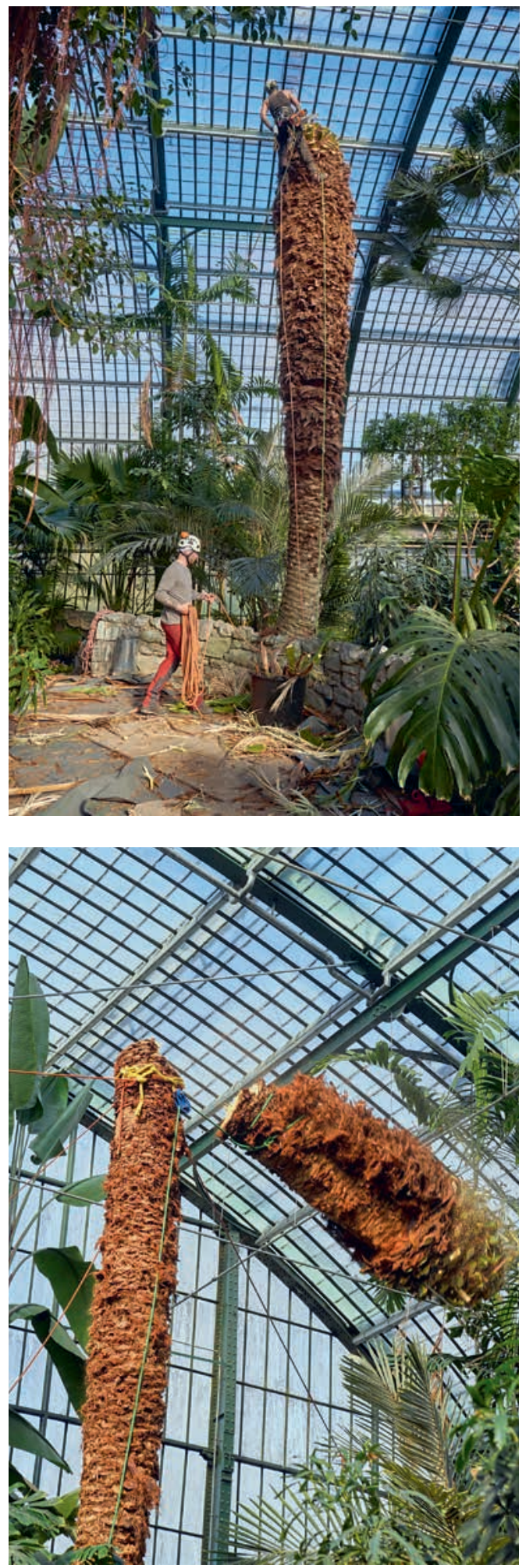
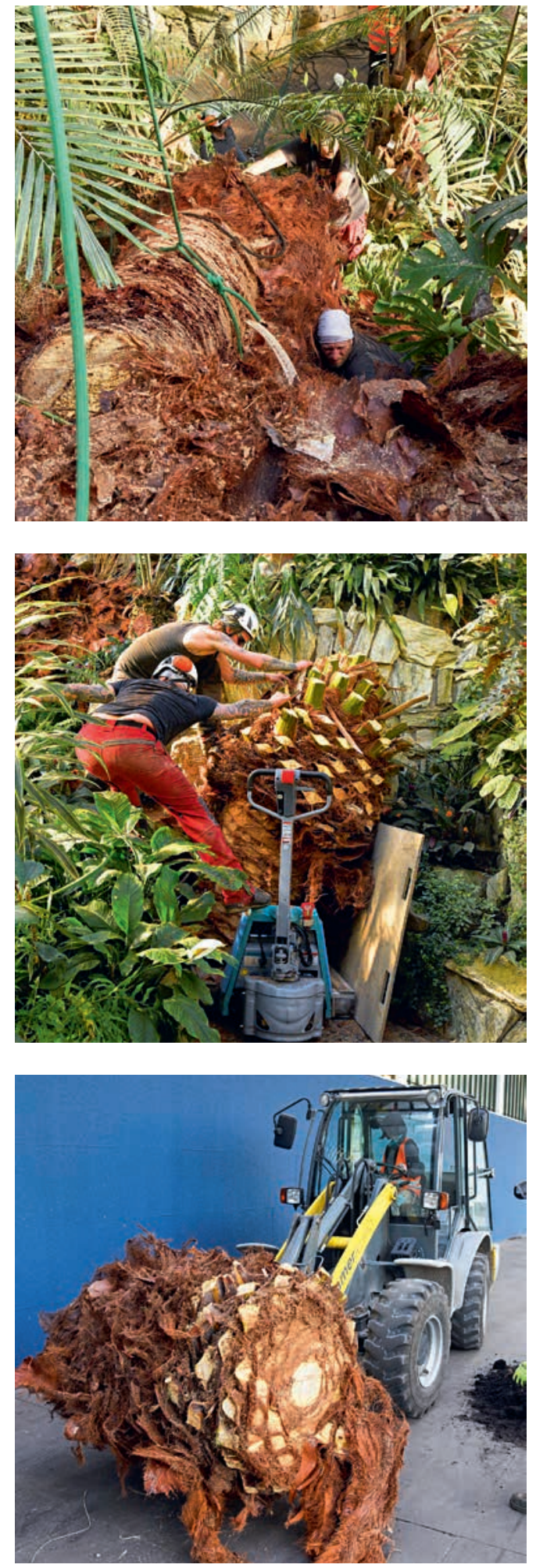